\title{
Roof Integrated Mini-Parabolic Solar Collectors. Comparison Between Simulation and Experimental Results
}

\author{
M. Petrakis*, G. Barakos and S. Kaplanis \\ Technological Educational Institute of Patras, Department of Mechanical Engineering, M. Alexandrou 1, Patra, Greece
}

\begin{abstract}
Concentrating solar collectors systems and especially the mini Parabolic solar reflecting systems have been one of the main research topics due to their ability for integration into the building structure. In the present work the mini parabolic collector was considered in the East - West orientation with such a slope so that the suns vector impinging normal to the parabola during the day. The behavior of the thermal efficiency for various values of small concentrating ratios and mass flow rate was studied. Data input such as solar radiation (direct and diffuse) and temperature ambient were obtained by the meteorological station of R.E.S. Laboratory in the Technological Educational Institute of Patras. The fluid inlet and outlet temperatures in the absorber, the total solar radiation incident on the aperture surface, the ambient temperature and the fluid flow measurements were managed using a data logging system. The paper presents a comparison between theoretical and experimental results.
\end{abstract}

Keywords: Mini parabolic collectors, thermal efficiency.

\section{INTRODUCTION}

Many researchers have investigated the concentrating systems of different sizes, scale and application type [1-3]. These systems are capable to achieve big outlet temperatures at low cost prices, which imply high enthalpy. It is possible to use them in thermal - power plants, hot water production for heating, and also solar air conditioning [1-6]. Particular interest is shown for roof integrated Parabolic Collectors and especially for mini parabolic collectors in order to remain the aesthetic of buildings unaffected. The research of such systems is under progress and only a few projects are mentioned and monitored [7, 8, 9]. In order to increase the system performance, roof integrated solar heating systems with glazed collector have been designed and investigated [10]. The target of this work is the comparison between theoretical and experimental results of the efficiency parameters of a special design and construction mini parabolic reflecting collectors (Fig. 1) [11, 12, 13].

The research was focused on the reliability of the performance and the optimization of the geometrical and physical characteristics as to maximize the output. There is, also, an interest about the stability of the performance and especially on some parameters concerning the constancy of flow rate, the accurate parabola trough construction, which may appear during the experimental procedure. In addition, was used a controlled heating device, which allows for test experiments to be performed with the input temperature steps increasing and followingly decreasing in preset values.

The theoretical analysis of the efficiency, the geometrical parameters, thermal and optical characteristics of the mini parabolic collector system, along with the system

\footnotetext{
*Address correspondence to this author at the Technological Educational Institute of Patras, Department of Mechanical Engineering, M. Alexandrou 1, Patra, Greece; E-mail: petrakis@teipat.gr
}

configuration (orientation, inclination, and disposition) are taken into account in the determination of the system's efficiency.

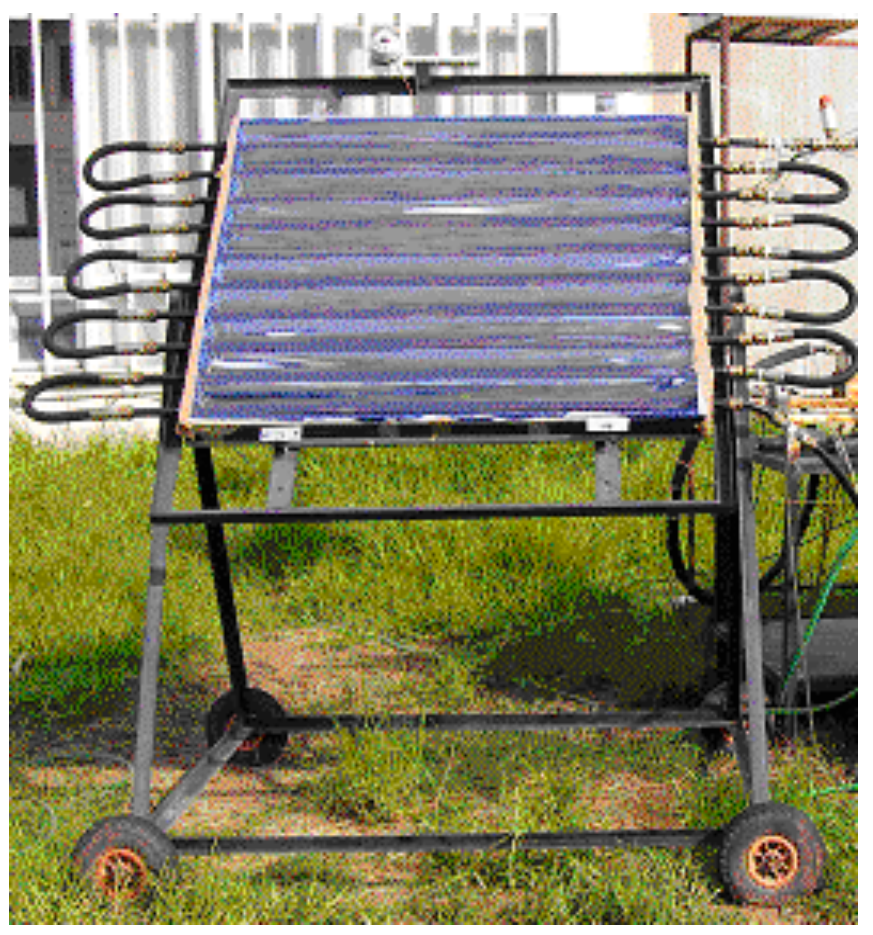

Fig. (1). A mini parabolic system of 10 reflecting parabolas connected in series constructed in the R.E.S. Laboratory.

Experimental measurements of the system's performance have been carried out based on A.S.H.R.A.E. 93/97 standard [14]. An automated electronic system (Fig. 2) to heat inlet water at predetermined temperatures was used. In this device, a data acquisition system (CR-1000 Data logger) to record all the needed quantities is also used. The experimental layout concerns measurements to determine the collec- 


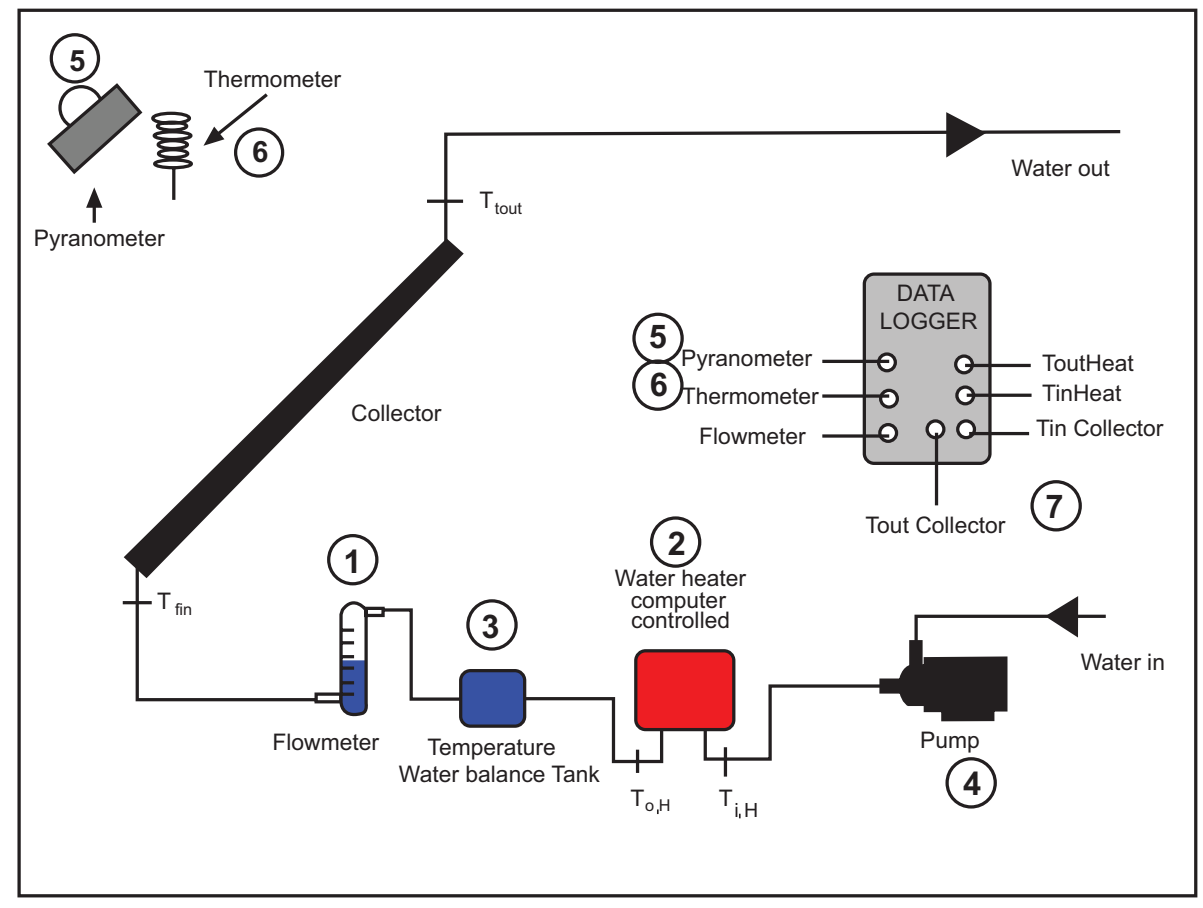

Fig. (2). Schematic representation of experimental device according to ASHRAE standard.

tor's thermal efficiency, under steady-state situations, in various operating conditions.

\section{MATHEMATICAL MODEL}

In this section we present a brief report of the mathematical expressions, which are used in the simulation model, such as:

1. The geometric expressions which describe parabolic reflecting solar collectors.

2. The determination of solar vector towards the parabola and the solar intensity on parabolic and tubular surfaces.

3. The physical parameters of the elements which compose the mini parabolic trough collector (P.T.C.).

4. The energy losses, optical and thermal.

The numerical code developed used FORTRAN 4.0 and models:

1. The building's roof.

2. The impinging solar radiation.

3. The reflection and absorption of the solar beam and their conversion to heat.

The geometric dimensions are opted for roof integration. The reflectance, emissivity and the absorptance of the re- flecting material (anodized $\mathrm{Al}$ ) and the absorber tube (copper painted black), respectively are:

- Parabola reflectance: $\rho=0.90$

- Tube absorptance: $\alpha=0.90$

- Parabola emissivity: $\varepsilon_{\mathrm{q}}=0.10$

- Tube emissivity: $\varepsilon_{\mathrm{c}}=0.80$

The input data required by the code are: day of the year, ambient temperature $T_{\alpha}$, building parameters (orientation, roof inclination) collectors positioning and geometric characteristics, measured instant incident radiation intense direct and diffuse.

The sun's unit vector is given (Fig. 3) by the well-known equation

$\mathrm{n}_{\mathrm{s}}=\cos \alpha \cos \gamma_{\mathrm{s}} \overrightarrow{\mathrm{i}}+\cos \alpha \sin \gamma_{\mathrm{s}} \overrightarrow{\mathrm{j}}+\sin \alpha \overrightarrow{\mathrm{k}}$

with the components $\cos \alpha \cos \gamma_{\mathrm{s}}, \cos \alpha \sin \gamma_{\mathrm{s}}, \sin \alpha$.

The program, via an orthogonal transformation, determines the sun's unit vector with reference to a $\mathrm{O}\left(\mathrm{x}_{1}, \mathrm{y}_{1}, \mathrm{z}_{1}\right)$ system with an axis along the absorber's tube central line $\mathrm{x}_{1}$, the $y_{1}$ axis normal to $x_{1}$ and $z_{1}$ axis normal to the roof's plane (Fig. 4).

In this way the previous equation is deduced as follows:

$$
\overrightarrow{\mathrm{n}}_{\mathrm{s}}=\left(\overrightarrow{\mathrm{n}}_{\mathrm{s}}\right)_{\mathrm{x}_{1}} \overrightarrow{\mathrm{i}}_{1}+\left(\overrightarrow{\mathrm{n}}_{\mathrm{s}}\right)_{\mathrm{y}_{1}} \overrightarrow{\mathrm{j}}_{1}+\left(\overrightarrow{\mathrm{n}}_{\mathrm{s}}\right)_{\mathrm{z}_{1}} \overrightarrow{\mathrm{k}}_{1}
$$


with the components

$\left(\mathrm{n}_{\mathrm{s}}\right)_{\mathrm{x}_{1}}=\left(\overrightarrow{\mathrm{n}}_{\mathrm{s}} \cdot \overrightarrow{\mathrm{i}}_{1}\right)=+\cos \alpha \cos \mathrm{e} \cos \beta \cos \gamma_{\mathrm{s}}+$

$+\cos \alpha \sin \gamma_{\mathrm{s}} \sin \mathrm{e}-\sin \alpha \sin \beta \cos \mathrm{e}$

$\left(\mathrm{n}_{\mathrm{s}}\right)_{\mathrm{y}_{1}}=\left(\overrightarrow{\mathrm{n}}_{\mathrm{s}} \cdot \overrightarrow{\mathrm{j}}_{\mathrm{l}}\right)=+\cos \alpha \sin \gamma_{\mathrm{s}} \cos \mathrm{e}-$

$-\cos \alpha \cos \gamma_{\mathrm{s}} \sin \mathrm{e} \cos \beta+\sin \mathrm{e} \sin \alpha \sin \beta$

$\left(\mathrm{n}_{\mathrm{s}}\right)_{\mathrm{z}_{1}}=\left(\overrightarrow{\mathrm{n}}_{\mathrm{s}} \cdot \overrightarrow{\mathrm{k}}_{1}\right)=+\cos \alpha \cos \gamma_{\mathrm{s}} \sin \beta+\sin \alpha \cos \beta$

where, $\overrightarrow{\mathrm{i}}_{1}, \overrightarrow{\mathrm{j}}_{1}$ and $\overrightarrow{\mathrm{k}}_{1}$ are the unit vectors of the axis $\mathrm{x}_{1}, \mathrm{y}_{1}, \mathrm{z}_{1}$ respectively:

$\overrightarrow{\mathrm{i}_{1}}=\mathrm{l}_{1} \overrightarrow{\mathrm{i}}+\mathrm{m}_{1} \overrightarrow{\mathrm{j}}+\mathrm{n}_{1} \overrightarrow{\mathrm{k}}=$

$=\cos \beta \cos e \vec{i}+\sin e \vec{j}-\sin \beta \cos e \vec{k}$

$\overrightarrow{\mathrm{j}_{1}}=\mathrm{l}_{2} \overrightarrow{\mathrm{i}}+\mathrm{m}_{2} \overrightarrow{\mathrm{j}}+\mathrm{n}_{2} \overrightarrow{\mathrm{k}}=$

$=-\cos \beta \sin e \vec{i}+\cos e \vec{j}+\sin e \sin \beta \vec{k}$

$\overrightarrow{\mathrm{k}}_{1}=1_{3} \overrightarrow{\mathrm{i}}+\mathrm{m}_{3} \overrightarrow{\mathrm{j}}+\mathrm{n}_{3} \overrightarrow{\mathrm{k}}=\sin \beta \overrightarrow{\mathrm{i}}+\cos \beta \overrightarrow{\mathrm{k}}$

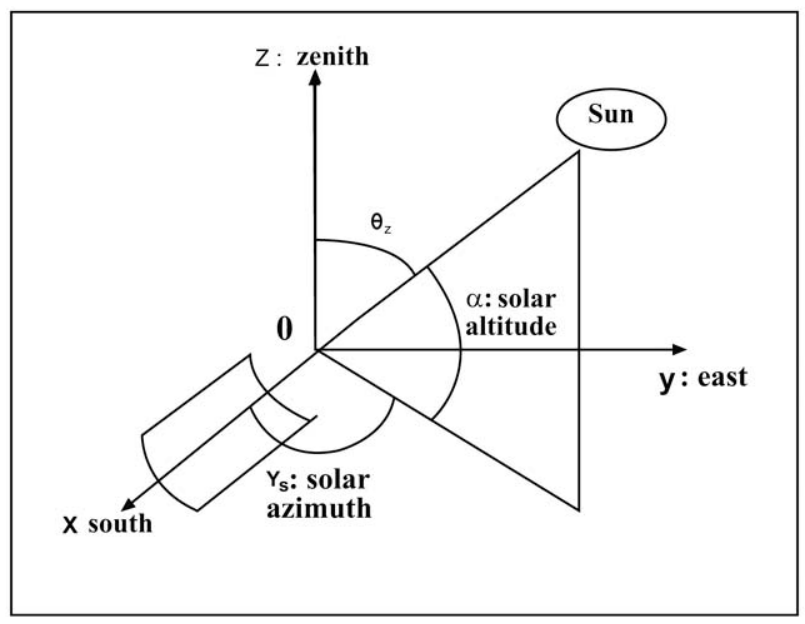

Fig. (3). Sun's position on $\mathrm{O}(\mathrm{x}, \mathrm{y}, \mathrm{z})$ coordinate system.

All parameters appeared in the next equations are described in the Table $\mathbf{1}$. is [8]:

The useful thermal energy rate delivered by the collector

$\mathrm{Q}_{\mathrm{u}}=\mathrm{Ac}\left[\mathrm{I}_{\mathrm{a}}-\mathrm{U}_{\mathrm{L}}\left(\mathrm{T}_{\mathrm{c}}-\mathrm{T}_{\mathrm{a}}\right)\right]$ or

$\mathrm{Q}_{\mathrm{u}}=\mathrm{F}_{\mathrm{R}} \mathrm{A}_{\mathrm{C}}\left[\mathrm{I}_{\mathrm{a}}-\mathrm{U}_{\mathrm{L}}\left(\mathrm{T}_{\mathrm{fi}}-\mathrm{T}_{\mathrm{a}}\right)\right]$

The optical efficiency $\eta_{\text {op }}$ is defined as the fraction of the solar radiation incident on the aperture of the collector, which is absorbed at the surface of the absorber tube.

$\eta_{\mathrm{op}}=\frac{\mathrm{I}_{\mathrm{a}} \mathrm{A}_{\mathrm{C}}}{\mathrm{I}_{\mathrm{T}} \mathrm{A}_{\mathrm{ap}}}$

then,

$\mathrm{Q}_{\mathrm{u}}=\eta_{\mathrm{op}} \mathrm{I}_{\mathrm{T}} \mathrm{A}_{\mathrm{ap}}-\mathrm{AcU}_{\mathrm{L}}\left(\mathrm{T}_{\mathrm{c}}-\mathrm{T}_{\mathrm{a}}\right)$,

or

$\mathrm{Q}_{\mathrm{u}}=\mathrm{F}_{\mathrm{R}}\left[\eta_{\mathrm{op}} \mathrm{I}_{\mathrm{T}} \mathrm{A}_{\mathrm{ap}}-\mathrm{A}_{\mathrm{C}} \mathrm{U}_{\mathrm{L}}\left(\mathrm{T}_{\mathrm{fi}}-\mathrm{T}_{\mathrm{a}}\right)\right]$

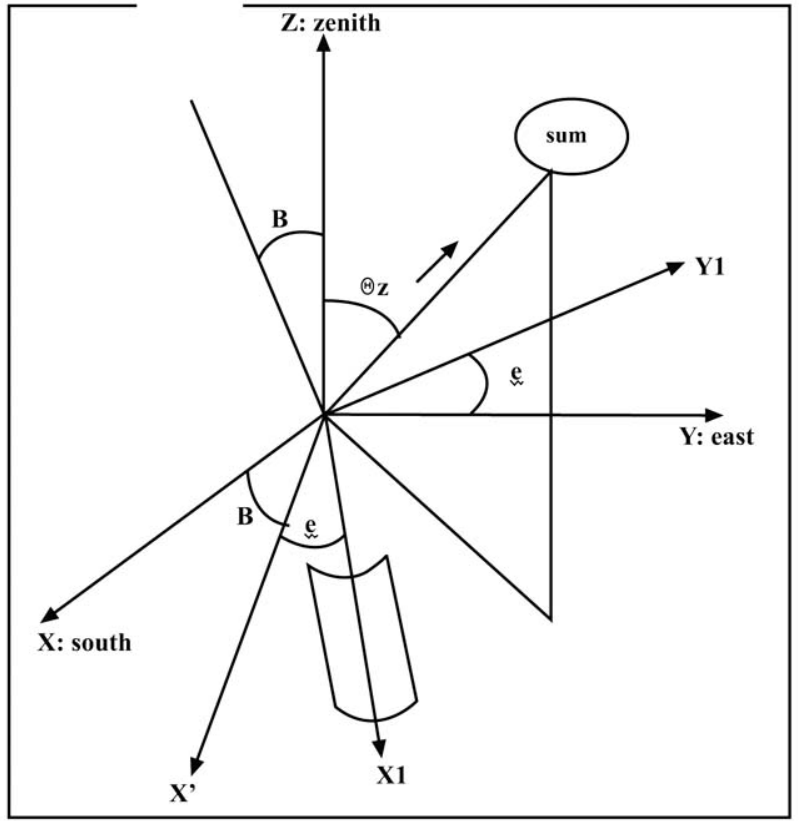

Fig. (4). Sun's and collector's position with reference to $\mathrm{O}\left(\mathrm{x}_{1}, \mathrm{y}_{1}\right.$, $\mathrm{z}_{1}$ ) system fixed on the parabola's focal axis which coincides with the absorber's axis.

Another expression of the useful heat gain rate is:

$\mathrm{Q}_{\mathrm{u}}=\dot{\mathrm{m}} \mathrm{C}_{\mathrm{p}}\left(\mathrm{T}_{\mathrm{fo}}-\mathrm{T}_{\mathrm{fi}}\right)[\mathrm{W}]$

Table 1 Basic Used Parameters

\begin{tabular}{|c|c|}
\hline $\mathrm{I}_{\mathrm{T}}$ & The intense of solar radiation incident on the aperture \\
\hline $\mathrm{I}_{\mathrm{a}}$ & The solar radiation intense absorbed by the absorber tube \\
\hline $\mathrm{A}_{\mathrm{c}}$ & The absorber tube receiver surface $\mathrm{A}_{\mathrm{c}}=\pi \mathrm{D}_{\mathrm{o}} 1$ \\
\hline $\mathrm{A}_{\mathrm{ap}}$ & The aperture surface $\mathrm{A}_{\mathrm{ap}}=2 \mathrm{y}_{\mathrm{s}} \cdot 1$ \\
\hline $\mathrm{D}_{\mathrm{o}}$ & The absorber tube external diameter \\
\hline 1 & The length of the trough parabola \\
\hline $\mathrm{U}_{\mathrm{L}}$ & The overall heat losses coefficient \\
\hline $\mathrm{T}_{\mathrm{c}}$ & The receiver temperature \\
\hline $\mathrm{T}_{\mathrm{a}}$ & The ambient temperature \\
\hline $\mathrm{T}_{\mathrm{fi}}$ & The inlet fluid temperature \\
\hline $\mathrm{F}_{\mathrm{R}}$ & The collector's heat removal factor \\
\hline$\dot{\mathrm{m}}$ & Fluid mass flow rate [kg/sec] \\
\hline $\mathrm{C}_{\mathrm{p}}$ & Specific heat capacity of the fluid $[\mathrm{J} / \mathrm{kgK}]$ \\
\hline $\mathrm{T}_{\mathrm{fo}}, \mathrm{T}_{\mathrm{fi}}$ & The overall heat transfer coefficient \\
\hline $\mathrm{U}_{0}$ & Thet and inlet temperatures respectively \\
\hline
\end{tabular}

The instantaneous collector's thermal efficiency $\eta_{p}$ is defined as the ratio of the useful energy delivered to the energy incident on the aperture:

$\eta_{\mathrm{p}}=\frac{\mathrm{Q}_{\mathrm{u}}}{\mathrm{I}_{\mathrm{T}} \mathrm{A}_{\mathrm{ap}}}$ 
The instant thermal efficiency of the collector becomes:

$\eta_{\mathrm{p}}=\eta_{\mathrm{op}}-\frac{\mathrm{U}_{\mathrm{L}}\left(\mathrm{T}_{\mathrm{C}}-\mathrm{T}_{\mathrm{a}}\right)}{\mathrm{I}_{\mathrm{T}}}$, or

$\eta_{p}=F_{R}\left[\eta_{o p}-\frac{A_{C}}{A_{a p}} \frac{U_{L}\left(T_{f i}-T_{a}\right)}{I_{T}}\right]$

According to equation (10) the difference between the values of the optical efficiency $\eta_{\text {op }}$ and the thermal efficiency $\eta_{p}$ is a measure of the losses due to re-radiation and convection from the absorber to the surroundings.

The losses occurring in the collector may be distinguished, in optical and thermal. Optical losses are those, which occur in the path of the incident solar radiation before it is absorbed at the surface of the absorber tube. Thermal losses are due to convection and re-radiation from the absorber tube and conduction through the ends and supports. Thermal losses from the receiver must be calculated, usually in terms of energy loss coefficient $\mathrm{U}_{\mathrm{L}}$, which is based on the area of the receiver.

The generalized thermal analysis of a concentrating collector is similar to that of a flat plate collector. It is necessary to derive appropriate expressions for the collector efficiency factor $\mathrm{F}^{\prime}$, the energy loss coefficient $\mathrm{U}_{\mathrm{L}}$ and the collector heat removal factor $F_{R}$. With $F_{R}$ and $U_{L}$ known, the collector useful thermal gain can be easily calculated.

For an uncovered cylindrical absorbing tube that might be used as a receiver in a linear concentrating system we calculate the thermal loss coefficient $\mathrm{U}_{\mathrm{L}}$ with the assumption that there are no temperature gradients around to the receiver tube.

In order to have more accurate results, the calculation of the heat loss coefficient $U_{L}$ is based on a combination of models, referred in bibliography $[15,16]$. Both of optical and thermal losses can be estimated by simulating methods.

\section{SIMULATION MODEL}

A simulation procedure has been developed in "FORTRAN 4.0" to study theoretically mini parabolic collectors [12].

The program chooses a series of equal space segment, $\mathrm{N}_{\mathrm{s}}$, on the parabola's aperture where the solar beam radiation impinges (Fig. 5).

This number was set equal to 64 or 128 or 256 or 512 or 1024. The higher $\mathrm{N}_{\mathrm{s}}$ are, the more accurate the results are and more execution true is required.

In Fig. (5) it is shown the reflecting parabola and the absorber section in a plane parallel to $\mathrm{y}_{1}, \mathrm{z}_{1}$ at the position $\mathrm{x}_{1}$, where $f$ is the focal distance and $h$ the depth of the parabola.

Initially, the program takes under consideration the direct and the diffuse component of solar radiation and finally, it summarizes the effects of both components. The scanning starts from the point $\mathrm{A}\left(0,-\mathrm{y}_{\mathrm{s}}, \mathrm{z}_{\mathrm{d}}\right)$ and finishes at
$\mathrm{A}^{\prime}\left(0, \mathrm{y}_{\mathrm{s}}, \mathrm{z}_{\mathrm{d}}\right)$ one, where $\mathrm{AA}^{\prime}$ is the aperture of the parabola.

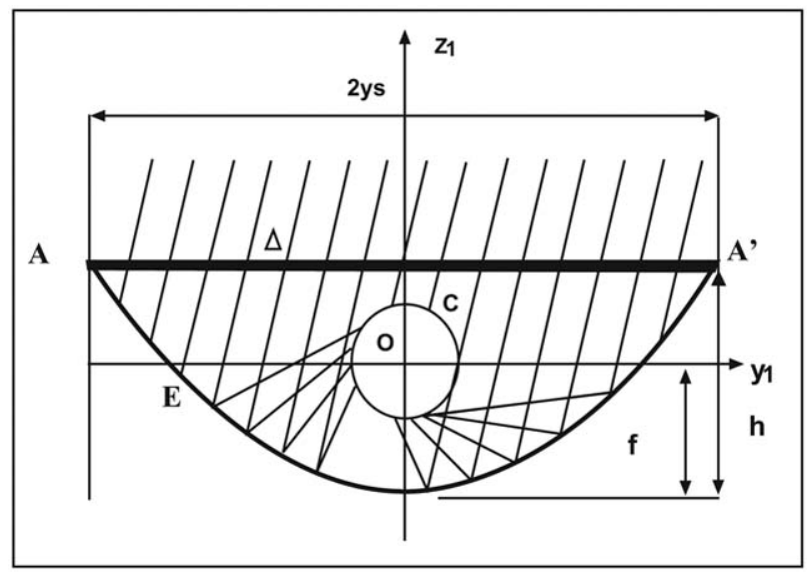

Fig. (5). Reflecting parabola and absorber on the plane $\left(\mathrm{y}_{1}, \mathrm{z}_{1}\right)$.

The sunrays are considered to be uniformly and parallel impinging on the parabola's aperture. For every point on the aperture, $\left(\mathrm{N}_{\mathrm{s}}+1\right)$ points, the program initially checks if the beam hits the absorber directly, or after reflecting on the parabola surface. Then, the point and angle of incidence on the absorber is determined, (Figs. 6, 7, respectively).

At the same time the power impinging on the relative absorber arch given by the equations (11) and (12) is calculated.

$$
\begin{aligned}
& \mathrm{P}_{\mathrm{bd}}=\mathrm{I}_{\mathrm{b}} \frac{\cos \theta}{\sin \alpha} \cdot \mathrm{s} \cdot 1 \cdot \cos \theta_{\mathrm{id}} \cdot \mathrm{a}[\mathrm{W}] \\
& \mathrm{P}_{\mathrm{br}}=\mathrm{I}_{\mathrm{b}} \frac{\cos \theta}{\sin \alpha} \cdot \mathrm{s} \cdot \mathrm{l} \cdot \mathrm{r} \cdot \cos \theta_{\mathrm{ir}} \cdot \mathrm{a}[\mathrm{W}]
\end{aligned}
$$

where, $s=\frac{2 y_{s}}{N_{s}}$ is the step on the aperture $2 y_{s}, 1$ is the length of the parabola trough, a is the receiver's absorption and $r$ is parabola's reflectance.

The ratio of the power to the relative correspondent surface of the cylinder arc $\mathrm{R} \cdot \mathrm{d} \lambda \cdot 1$ gives the intense in $\left[\mathrm{W} / \mathrm{m}^{2}\right]$. Finally, the program stores the coordinates of the points of the absorber where the beam radiation has been absorbed.

To determine the points where the diffuse radiation hit the absorber either directly or reflectively as well as the optical and energy efficiency we use the Monte Carlo method [17].

In the isotropic model the angle $\varphi_{\mathrm{R}}$ is uniformly distributed between the values 0 and $2 \pi$, while $\cos \theta_{R}$ is uniformly distributed between the values 0 and 1 (Fig. 8).

To choose values for $\varphi_{R}$ and $\theta_{R}$ we use a random number generator, which provides $R_{1}$ and $R_{2}$, then $\varphi_{R}=2 \pi R_{1}$ and $\cos \theta_{\mathrm{R}}=1-\mathrm{R}_{2}[17]$. 


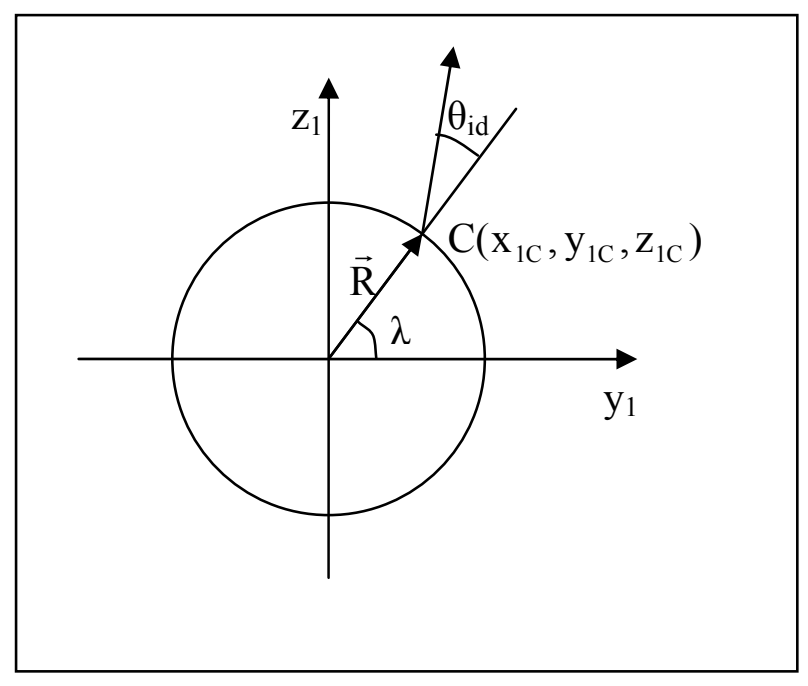

Fig. (6). Beam directly impinging the absorber.

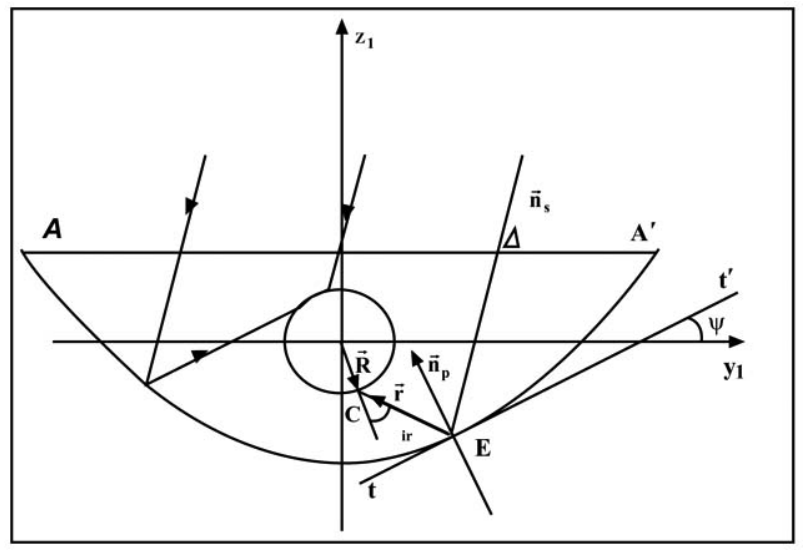

Fig. (7). Schematic representation of direct beam incident after reflection.

The random diffuse isotropic radiation unit vector $\overrightarrow{\mathrm{n}}_{\mathrm{d}}=\overrightarrow{\Delta \mathrm{K}}$ has the components on the coordinate system $\mathrm{x}_{1}, \mathrm{y}_{1}, \mathrm{z}_{1}$ :

$\mathrm{n}_{\mathrm{dx} 1}=\sin \theta_{\mathrm{R}} \sin \varphi_{\mathrm{R}}$

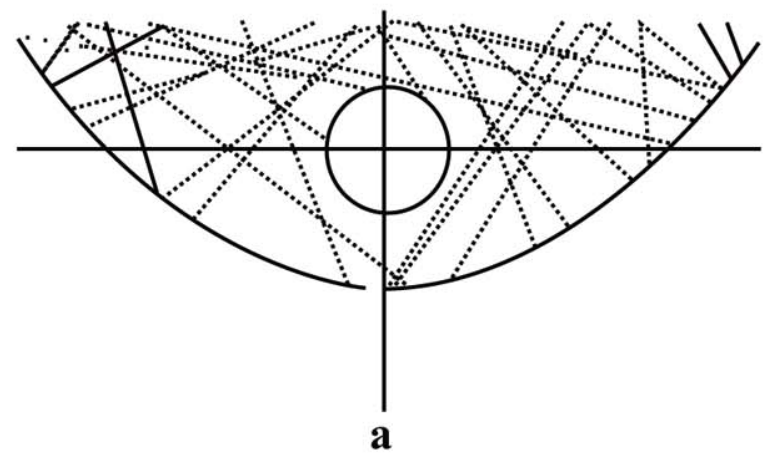

$$
\begin{aligned}
& \mathrm{n}_{\mathrm{dy} 1}=\sin \theta_{\mathrm{R}} \cos \varphi_{\mathrm{R}} \\
& \mathrm{n}_{\mathrm{dz} 1}=\cos \theta
\end{aligned}
$$

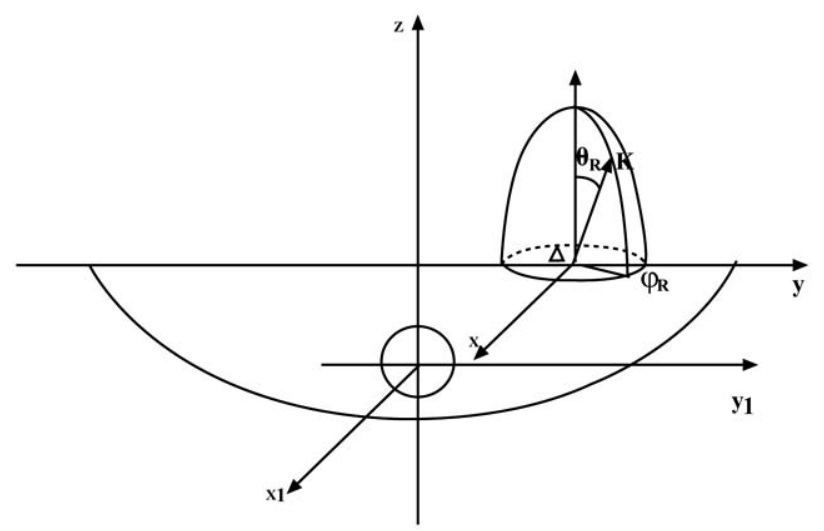

Fig. (8). Isotropic diffuse radiation - Monte Carlo Techniques.

The program checks initial if the random diffuse ray presented by the above equation hits the absorber directly. Then it determines the point and angle of incidence on the absorber. If the diffuse solar equation line intersects the parabola the program checks the reflected diffuse rays that hit the absorber.

The diffuse radiation directly impinging the absorber and the diffuse radiation incident on the absorber after reflection on the parabolas surface is investigated in the following subsection.

The program stores the coordinates of the absorber's points where the diffuse radiation has hit and gives the profile of these points (Fig. 9).

\section{EXPERIMENTAL LAY_OUT DESCRIPTION}

Fig. (10) shows the experimental setup components:

The geometric characteristics of the system are summarized in theTable 2 .

For the purpose of this research in the R.E.S. Laboratory with the comprehensive collaboration of the C.N.C. Laboratory, have been constructed two mini - parabolic systems. For the construction of the reflecting parabola aluminum foils type MIRO 27-Hochglanz - extra bright with special PVD coating from ALANOD Company were used.

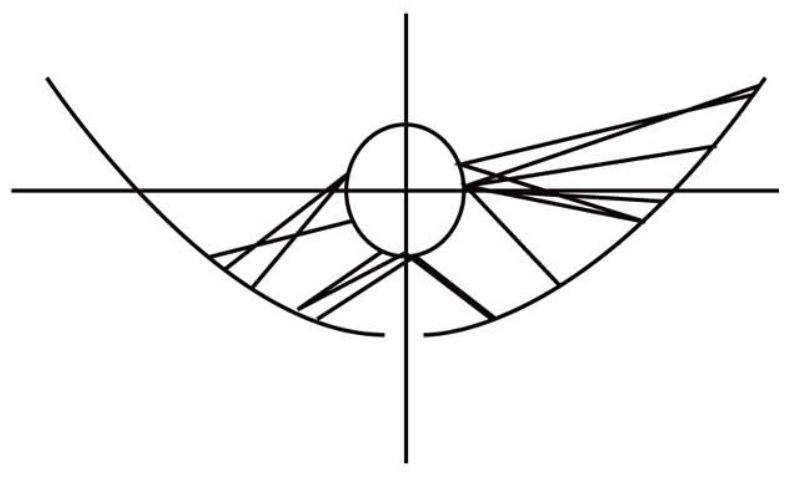

b

Fig. (9). Ray trace diagram for diffuse radiation, impinging the absorber. (a) directly, (b) after reflection. 


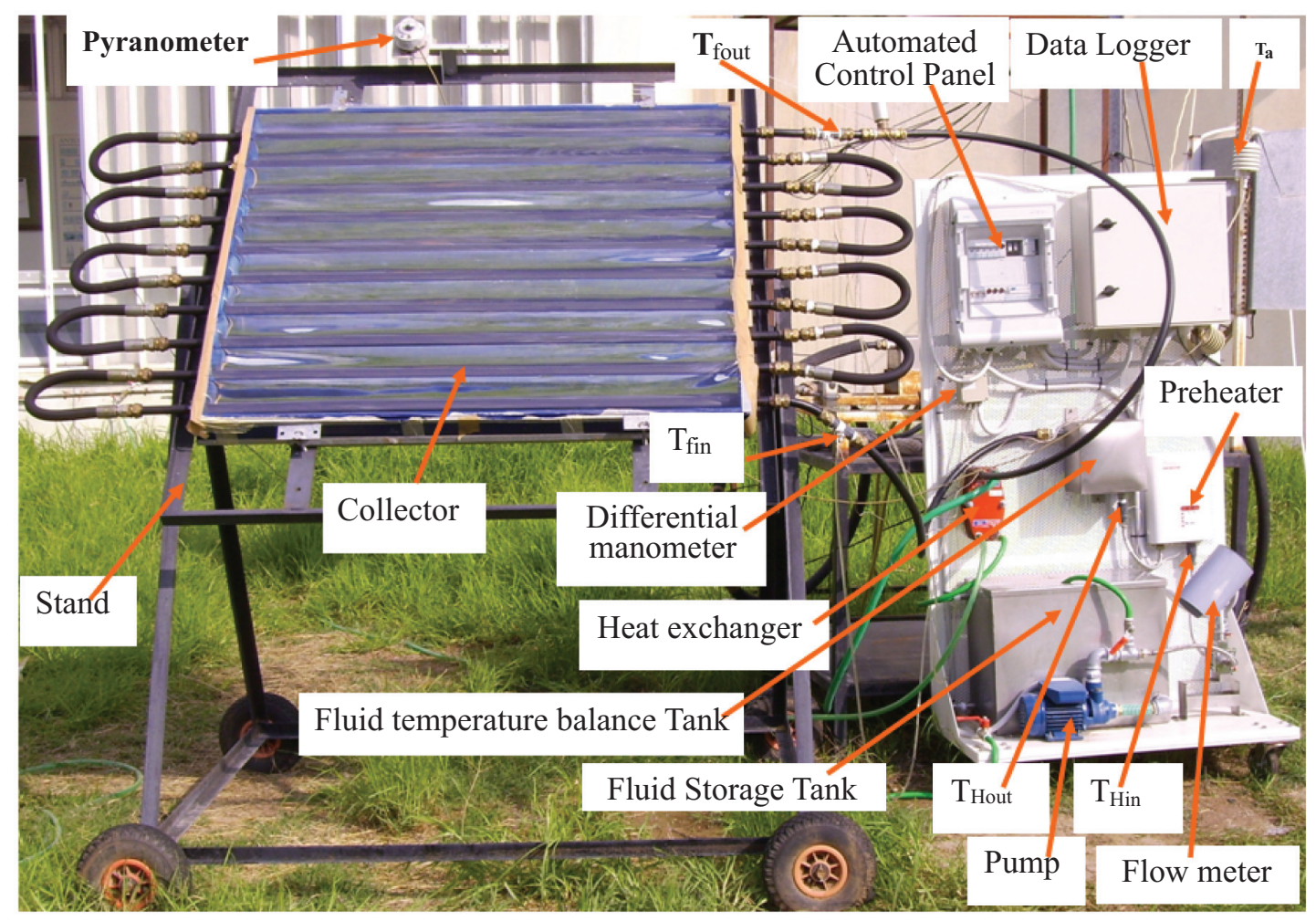

Fig. (10). Experimental lay - out components.

As absorber, copper tubes with external diameters Do $=$ $22 \mathrm{~mm}, 15 \mathrm{~mm}$ were used. The cooper tubes were painted black. As the possibility to adjust absorber tubes diameter exists, every constructed collector studied with both absorber diameters $(\mathrm{Do}=22 \mathrm{~mm}, 15 \mathrm{~mm})$.

\section{Table 2. Geometric Characteristics of the System}

\begin{tabular}{|l|}
\hline Length: $\mathrm{L}=1.25 \mathrm{~m}$ \\
\hline Collector depth: $\mathrm{D}_{\mathrm{c}}=60 \mathrm{~mm}$ \\
\hline Parabola depth: $\mathrm{h}=50 \mathrm{~mm}$ \\
\hline Aperture of channel parabola: $2 \mathrm{y}_{\mathrm{s}}=100 \mathrm{~mm},: 2 \mathrm{y}_{\mathrm{s}}=160 \mathrm{~mm}$ \\
\hline Total aperture: $\mathrm{A}_{\text {aptot }}=1.20 \mathrm{~m}^{2}, 1.25 \mathrm{~m}^{2}$ \\
\hline Absorber tube diameter: $\mathrm{Do}=22$ and $15 \mathrm{~mm}$ \\
\hline Foil thickness: $\mathrm{S}_{\mathrm{f}}=0.5 \mathrm{~mm}$ \\
\hline Absorber tube thickness: $\mathrm{S}_{\mathrm{l}}=1 \mathrm{~mm}$ \\
\hline Concentration ratio: $\mathrm{C}=1.45$ and 2.12 \\
\hline Focal distance: $12.5 \mathrm{~mm}, 32 \mathrm{~mm}$ \\
\hline Parabola reflectance: $\mathrm{r}=0.90$ \\
\hline Tube absorptance: $\alpha=0.90$ \\
\hline Parabola emissivity: $\varepsilon_{\mathrm{q}}=0.10$ \\
\hline Tube emissivity: $\varepsilon_{\mathrm{c}}=0.80$ \\
\hline
\end{tabular}

The absorbers can be connected in series or in parallel. In this work is used only the connection in series (Fig. 11).

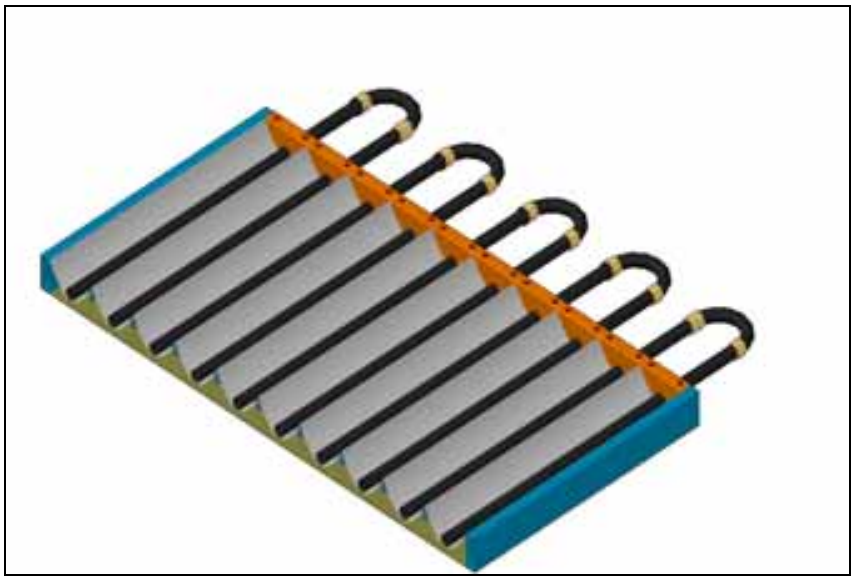

Fig. (11). Absorber connection in series.

Experimental measurements of the system's performance have been carried out using a test facility based on ASHRAE standard 93-97 [14] (Fig. 2). An automated electronic system to heat inlet water at predetermined temperature is used. In this device we use for data acquisition system a (CR - 1000 Data logger) to record all the needed quantities.

The experimental lay - out (Fig. 10) concerns measurement about the determination of the collector's thermal efficiency under steady-state conditions, in various operation conditions. It is performed according to the following procedure:

step 1. The collector is placed on a stand, which can be moved in such a way that: 
a. The orientation and inclination of the collector can be set in different

dispositions in order to correspond to any buildings roof geometry and

topography.

b. The collector's panel orientation can be set in two positions, east - west

and north - south.

step 2. The different trough parabolas can be connected in series or in parallel.

step 3. Water flows through the collector at a constant flow rate during all

measurements of a set of experiment. Generally the flow rate is adjustable.

step 4. The temperature inlet water is predetermined using an automated electronic system.

step 5. Assuming that the whole system is under steady state conditions, the following

quantities are measured:

i) The Global Solar Irradiation Intense on the collectors' plane by the pyranometer that is installed on the collectors stand.

ii) The ambient air temperature using a thermometer that is installed in the test area.

iii) Water mass flow rate using a flow meter.

iv) The inlet and outlet fluid temperatures of the collector using thermocouples.

step 6. Measurements of solar radiation, global and diffuse, are also obtained from the meteorological station of the R.E.S. Laboratory.

As mentioned above we have constructed two collector concentrating systems one with 6 parabola troughs $1.25 \mathrm{~m}$ long of total aperture $6 \times 0.160 \times 1.25=1.20 \mathrm{~m}^{2}$ and one with 10 parabola troughs $1.25 \mathrm{~m}$ long of total aperture $10 \times .0 .100$ x $1.25=1.25 \mathrm{~m}^{2}$ (Fig. 12a,b).

(a)

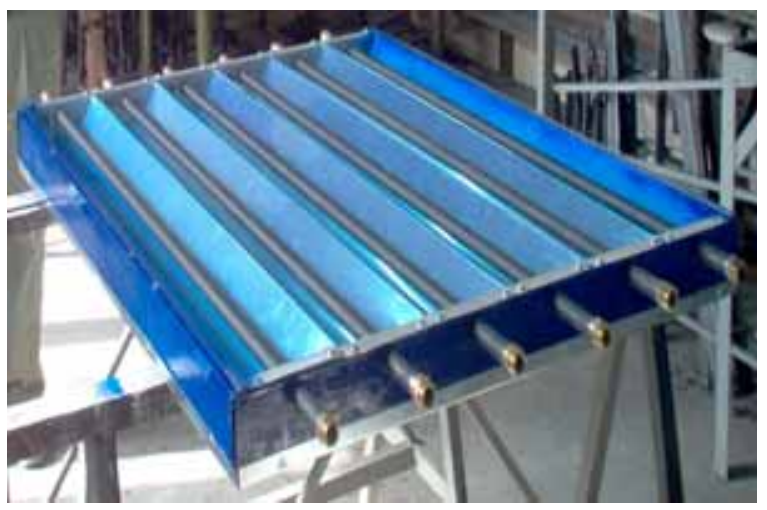

The collectors inclination to horizontal was taken to insure that solar beam impinges normal to the aperture of the parabola during experiments were caring out. Collector's orientation is south and its disposition is East - West.

There will be an effort to determine experimentally the instant thermal efficiency for those collectors over different days and conditions.

The experimental values of the collector's thermal efficiency compared to those obtained from the simulation software were done for the evaluation of software's reliability.

In the simulation model developed, the values of direct and diffuse solar radiation can be given from the pyranometers, installed on the experimental lay - out and the meteorological station of our laboratory.

Various fluid mass flow rates and inlet fluid temperature were used. The fluid was ordinary city water.

Measurements have been carried out during clear days in October and November in Patras. Measured data are stored and processed by means of a data acquisition system.

The system should allow both, to experimentally validate simulation program of thermal behavior and to compare results of thermal efficiency obtained through theoretical predictions and through measurements. It should also demonstrate and evaluate the efficiency of the constructed mini parabolic trough collectors.

Experiments were set up on the south oriented parabolic collector's panel for the exact orientation a precision compass was used. All instruments are connected to a data logger system.

\section{RESULTS}

The theoretical results were obtained for around the solar noon period. That was due to the fact that in the experimental analysis, there appear some observations about the influence of the concentration ratio, $\mathrm{C}$, on the final output, for time periods far from the solar noon, when the angle of incidence gets high values.

Therefore, this analysis is important in order to investigate the effect of reflected solar beam incident on the absorber and especially its angle of incidence for various P.T.C. systems with various $C$ values.

Fig. (12). Six and ten troughs parabolic collector respectively. 
In fact, for a period around solar noon the angle of incidence of the beam rays is in high majority of low values. On the other hand, as solar time moves away of the solar noon before or after, the angle of incidence becomes quite higher and therefore this implies a behavioral change in the PTC energy performance.

To obtain the simulation results, the meteorological data of the $335^{\text {th }}$ day, were used. In all cases it was considered that the solar radiation strikes the parabolic collector at normal, the system was facing south and has the right angle $\beta$. The package was executed for various concentration ratios $\mathrm{C}$, and different absorber tube diameters, fitted in the parabolic collector's focal axis. The total collector system consisted of 6 troughs in series as shown in Fig. (12).

The shape of the curve of thermal efficiency $\eta$ versus $\Delta \mathrm{T} / \mathrm{I}_{\mathrm{T}}$ as constructed by fitting the simulation results, is of second order. This shape is clear for large values of $\left(T_{\text {fin }}-T_{a}\right)$ while, as the value of $\left(\mathrm{T}_{\text {fin }}-\mathrm{T}_{\mathrm{a}}\right)$ decreases, the curves obtained are similar to the linear behavior (Figs. 13, 14).

The input data are analytically presented in Table $\mathbf{3}$.

In Fig. (13) it is presented the variation of the thermal efficiency $\eta$ versus $\Delta \mathrm{T} / \mathrm{I}_{\mathrm{T}}$ for different concentration ratios $\mathrm{C}$, $(3.395,6.369,10.185,16.976)$ under the same mass flow rate $72[1 / \mathrm{h}]$. As it was expected, better behavior was obtained from the parabolic collector with the higher concentration ratio. It can be seen that as the concentration ratio increases the rate of decrease of the efficiency versus $\Delta \mathrm{T} / \mathrm{I}_{\mathrm{T}}$ is smaller. This mean that the energy losses get smaller as the slope decreases. This implies that the parabolic collector systems with high concentration ratio $\mathrm{C}$ perform better when the generating point of the P.T.C. is in high $\Delta \mathrm{T} / \mathrm{I}_{\mathrm{T}}$ values.

In Fig. (14) the variation of the thermal efficiency, $\eta$, versus $\Delta \mathrm{T} / \mathrm{I}_{\mathrm{T}}$, keeping $\mathrm{C}$ constant, is shown. As it was expected higher thermal performance is obtained when the mass flow rate $\dot{\mathrm{m}}$ increases. The rate of decrease of the efficiency $\eta$ versus $\Delta \mathrm{T} / \mathrm{I}_{\mathrm{T}}$ is invariable, as the mass flow rate increases. However, this rate of change depends also on the generating point $\left(\mathrm{T}_{\text {fin }}-\mathrm{T}_{\mathrm{a}}\right) / \mathrm{I}_{\mathrm{T}}$. On the other hand, as the $\Delta \mathrm{T} / \mathrm{I}_{\mathrm{T}}$ increases the divergence between the curves for various values of $\dot{m}$ decreases. This is in contrast with those concluded previously (Fig. 13).

Table 3. Simulation Procedure Input Data

\begin{tabular}{|l|c|}
\hline \multicolumn{1}{|c|}{ Site } & Patra, Greece \\
\hline \hline Day/year & $335 / 2006$ \\
\hline Latitude $\varphi$ & $38.25^{\circ}$ \\
\hline Longitude 1 & $21.73^{\circ}$ \\
\hline Collector Type & 6 - trough parabolic collector \\
\hline Absorber tube diameter D & 3 mm, 5 mm, 8 mm, 15 mm \\
\hline Collectors Inclination $\beta$ & $60.35^{\circ}$ \\
\hline Collectors Orientation $\gamma$ & $0^{\circ}$ \\
\hline Collectors Disposition & East $-\mathrm{West}^{\circ}$ \\
\hline \multicolumn{1}{|c|}{ Measured Quantities } \\
\hline $\begin{array}{l}\text { Total Solar radiation impinging } \\
\text { normal to the collector's plane } \mathrm{I}_{\mathrm{T}}\end{array}$ & $936 \mathrm{~W} / \mathrm{m}^{2}$ \\
\hline $\begin{array}{l}\text { Diffuse Solar radiation on the } \\
\text { collector's plane } \mathrm{I}_{\mathrm{d}}\end{array}$ & $16.3^{\circ} \mathrm{C}$ \\
\hline Ambient Temperature $\mathrm{T}_{\mathrm{a}}$ & $220 \mathrm{~W} / \mathrm{m}^{2}$ \\
\hline
\end{tabular}

A further analysis investigates the dependence of $\eta$ on the value of the mass flow rate $\dot{\mathrm{m}}$. In Figs $(\mathbf{1 5}, \mathbf{1 6})$, the thermal efficiency $\eta$, versus the mass flow rate $\dot{m}$, at various concentration ratios $\mathrm{C}$, is shown, for inlet fluid temperatures, $\mathrm{T}_{\text {fin }} 20^{\circ} \mathrm{C}$ and $50^{\circ} \mathrm{C}$, respectively.

In the figures presented above, (Figs. 15, 16) it is evident that the thermal efficiency, $\eta$, saturates after a characteristic value of $\dot{m}$. This value becomes smaller, as $T_{\text {fin }}$ decreases. This saturation occurs for all values of the concentration ratios $\mathrm{C}$. For small mass flow rates, the thermal efficiency presents a very high rate of increase and this happens independently to fluid inlet temperatures. Small fluid inlet tem-

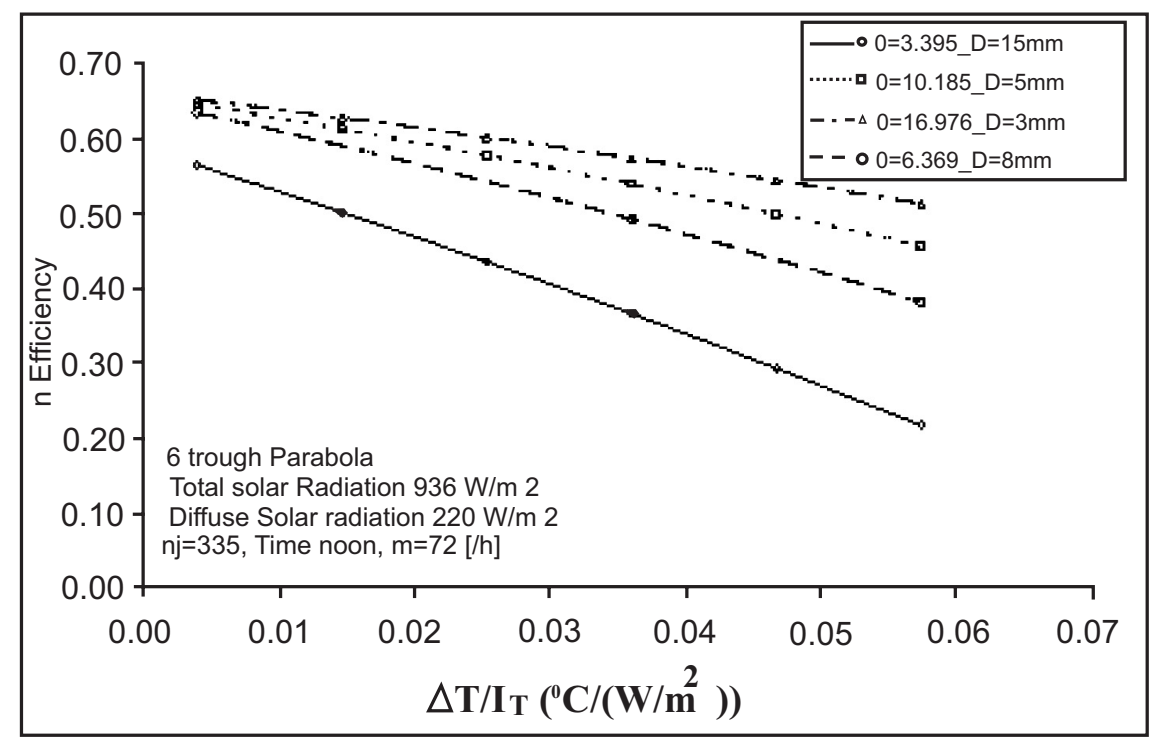

Fig. (13). Theoretical thermal efficiency $\eta$ versus $\Delta \mathrm{T} / \mathrm{I}_{\mathrm{T}}$ for different Concentration ratios, obtained by the simulation package. 


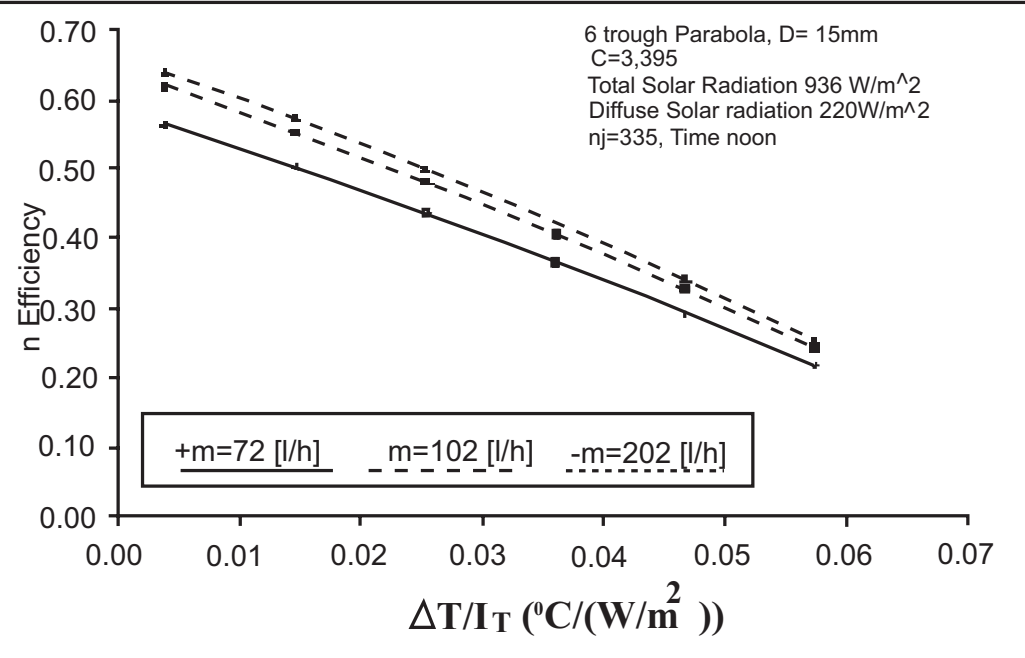

Fig. (14). Theoretical thermal efficiency versus $\Delta \mathrm{T} / \mathrm{I}_{\mathrm{T}}$ for different mass flow rates.

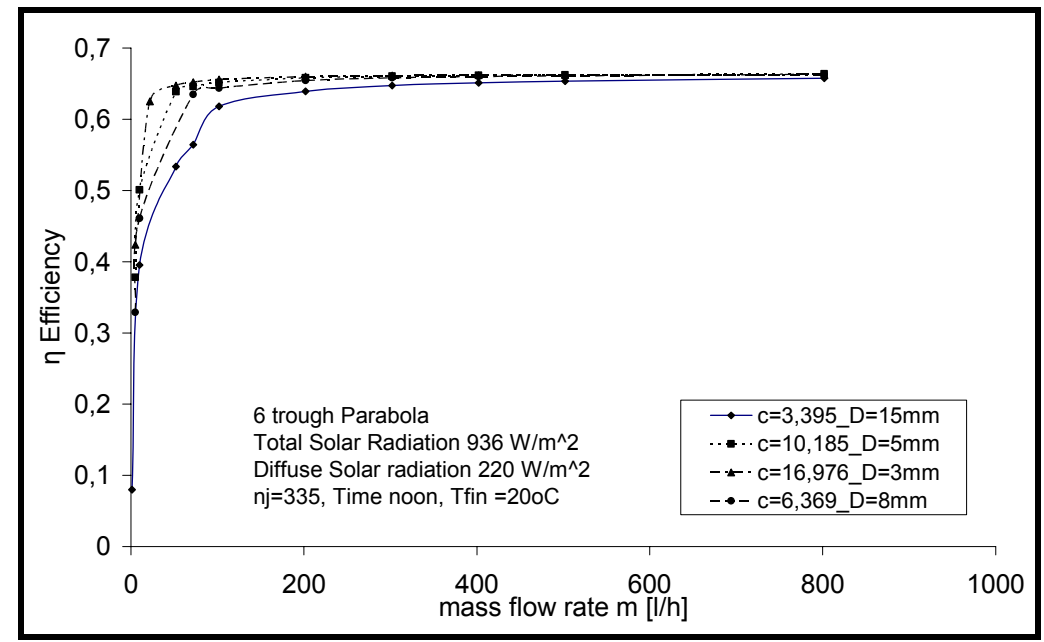

Fig. (15). Theoretical thermal efficiency $\eta$, versus the mass flow rate $\dot{\mathrm{m}}$, for various values of concentration ratios, $\mathrm{C}$ for $\mathrm{T}_{\text {fin }}=20^{\circ} \mathrm{C}$.

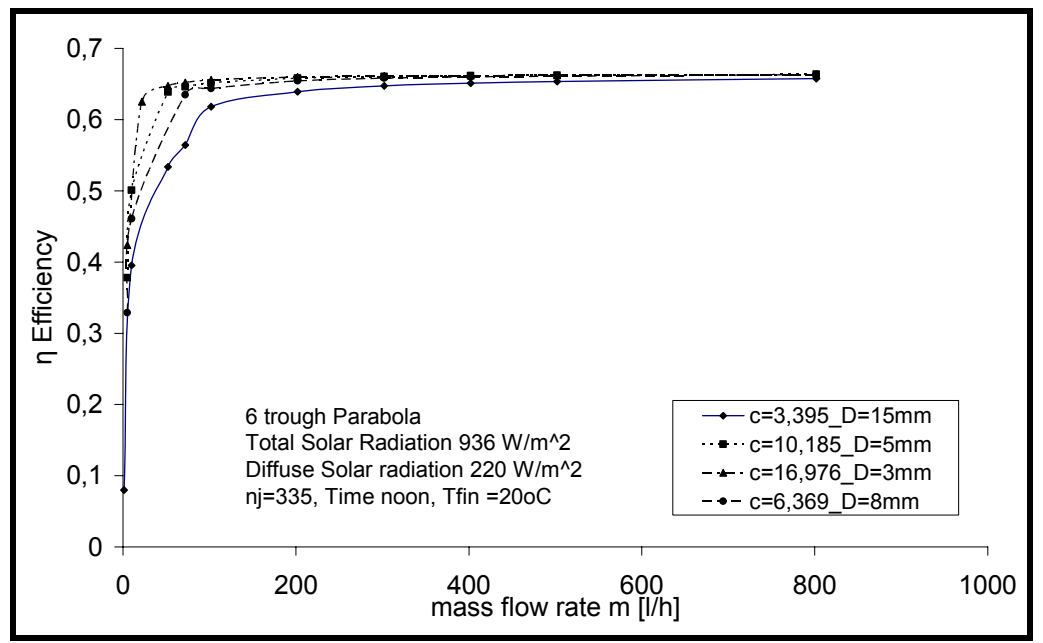

Fig. (16). Theoretical thermal efficiency $\eta$, versus mass flow rate $\dot{\mathrm{m}}$, for various values of concentration ratios, $\mathrm{C}$ for $\mathrm{T}_{\text {fin }}=50{ }^{\circ} \mathrm{C}$.

perature $\mathrm{T}_{\text {fin }}$ (Fig. 15) gives better results for high concentration ratios, only for small values of mass flow rate. Such values are lower than the optimum value of $\dot{\mathrm{m}} \quad(\dot{\mathrm{m}}=52$ $[1 / \mathrm{h}]$ ). However, as the fluid inlet temperature increases, (Fig.
16), the dependence of the efficiency $\eta$ on the concentration ratio $\mathrm{C}$ is more clear for all values of mass flow rates, $\dot{\mathrm{m}}$.

In the Figs. (17) and (18) it is shown the solar radiation for the specific days and hours. The experiments were trans- 


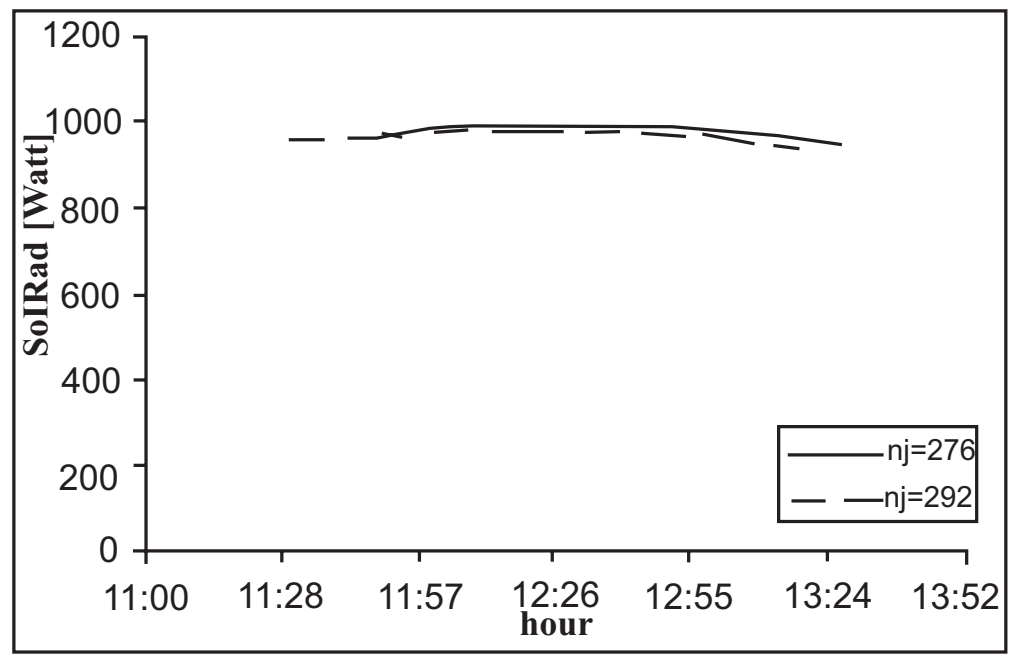

Fig. (17). The solar radiation versus the solar hour for the case of 276 and 292 day.

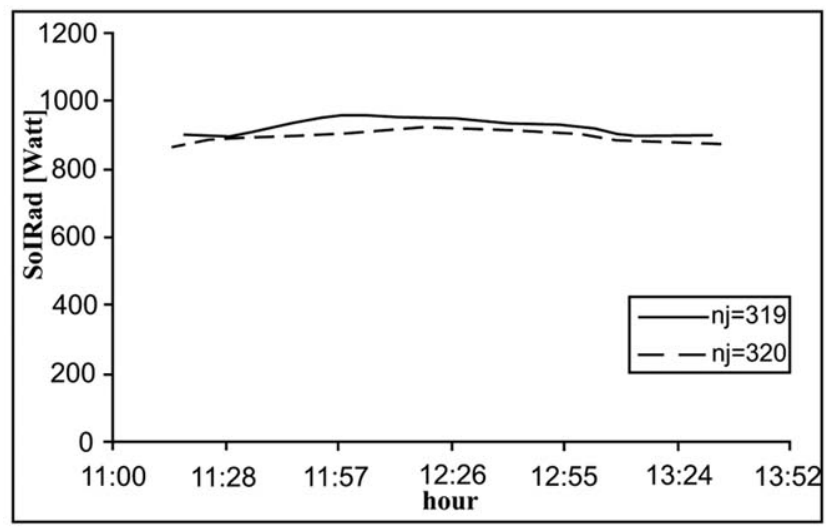

Fig. (18). The solar radiation versus the solar hour for the case of 319 and 320 day.

acted during four days of October and November. It is obvious that the solar radiation during the experiments remains almost constant.

The cases examined were for Patras city, in Greece. The collector inclination to horizontal was taken to secure that solar beam impinges normal to the aperture of the parabola during the experiments. The East-West (E-W) orientation was considered in all cases. Finally, the geometrical parameters, thermal and optical characteristics of the mini parabolic collector system, along with the system configuration (orientation, inclination, and disposition) are taken into account in the determination of the system's efficiency.

\section{CONCLUSIONS}

- $\quad$ As the concentration ratio increases the thermal efficiency increases, with mass flow rate constant, for periods around solar noon.

- $\quad$ As the mass flow rate increases the thermal efficiency increases around solar noon periods, for the same concentration ratios.

- $\quad$ The thermal efficiency increases as a function of mass flow rate but this increase reach a saturation for all concentration ratios.
- $\quad$ The saturation $\dot{\mathrm{m}}$ rate is lower for high $\mathrm{C}$, values when $\mathrm{T}_{\text {fin }}$ takes low values.

- For small mass flow rates, the thermal efficiency presents a very big rate of increase and this happens independently to fluid inlet temperatures.

\section{REFERENCES}

[1] Eanes, P.C.; Norton, B.; Tripanagnostopoulos, Y.; Yianoulis, P. Modelling line-axis solar concentrators in the medium temperature range. Renewable Energy, 1999, 16, 743-748.

[2] Eanes, P.C.; Norton, B. Validated Unified model for optics and heat transfer in line-axis concentrating solar energy collectors. Solar Energy, 1950, 50(4), 339-355.

[3] Sammouda, H.; Royere, C.; Belghith, A.; Maalej, M. Reflected radiance distribution law for a $1000 \mathrm{KW}$ thermal solar furnace system. Renewable Energy, 1999, 17, 9-20.

[4] Kothdiwala, A.F.; Eames, P.C.; Norton, B.; Zacharopolous, A Comparison between inverted absorber asymmetric and symmetric tubular-absorber compound parabolic concentrating solar collectors. Renewable Energy, 1999, 18, 277-281.

[5] Mills, D.R.; Morrison, G.L. Compact linear Fresnel reflector solar thermal power plants. Solar Energy, 2000, 68, 263-283.

[6] Radosevich, L.G.; Skinrood, A.C. The power production operation of solar one, the 10MW solar thermal central receiver pilot plant. $J$. Solar Energy Eng. Trans. ASME, 1989, 111, 144-151

[7] Proctor, P.M. Design and performance of a roof integrated solar air and heater. Solar Energy, 1983, 31, 183-189. 
[8] Saman, W.; Belusko, M. Transiration in a Roof Integrated Solar Heating System, Proceedings of Australian and New Zeeland Solar Energy Society Annual Conference, Christchurch, New Zeeland, 1998, pp. 555-562.

[9] Saman, W.; Belusko, M. Roof Integrated Heating and Cooling System, Proceedings of ISES World Congress, vol. II, Jerusalem, Israel, 2000; pp. 18- 26.

[10] Belusko, M.; Saman, W.; Bruno, F. Roof integrated solar heating system with grazed collector. Solar Energy, 2004, 76, 61-69.

[11] Barakos, G.; Kaplanis, S.N.; Petrakis M.A. Optical and Thermal Performance Simulation of Mini Parabolic Collectors with Several Geometries for Roof Integration, Proceeding of The International Conference on The Integration of The Renewable Energy Systems into the Building Structure, Patra, Greece, 2005; pp. 22-28.
[12] Barakos, G.; Kaplanis, S.N.; Petrakis M.A. Performance simulation of mini-parabolic reflecting collectors and experimental data, WREC IX, Florence Italy, 2006.

[13] Barakos, G.; Kaplanis, S.N.; Petrakis M.A.; Spyrogiannoulas, A. experimental and theoretical analysis of the performance of a miniparabolic solar reflecting collector, Congress of Heat Transfer and Renewable Sources of Energy, HTRSE, Szczecin, Poland, 2006, pp. 237-244.

[14] ASHRAE 93 -77. Method of Testing to Determine the Thermal Performance of Solar Collectors. American Society of Heating, Refrigeration, and Air Conditioning Engineers: New York, 1977.

[15] McAdams, W.H. Heat Transmission. McGraw-Hill: Tokyo, 1960.

[16] Incropera, F.P.; Dewitt, D.P. Introduction to Heat Transfer. John Wiley \& Sons: New York, 1996.

[17] Kaplanis, S.N. The Monte Carlo Method, Thessaloniki, 1978.

(C) Petrakis et al.; Licensee Bentham Open.

This is an open access article licensed under the terms of the Creative Commons Attribution Non-Commercial License (http://creativecommons.org/licenses/by$\mathrm{nc} / 3.0 /$ / / which permits unrestricted, non-commercial use, distribution and reproduction in any medium, provided the work is properly cited. 